\title{
Statins in the Prevention and Treatment of Heart Failure: a Review of the Evidence
}

\author{
Matthew M. Y. Lee ${ }^{1} \cdot$ Naveed Sattar ${ }^{1} \cdot$ John J. V. McMurray ${ }^{1} \cdot$ Chris J. Packard $^{1}$ \\ Published online: 27 July 2019 \\ (C) The Author(s) 2019
}

\begin{abstract}
Purpose of Review We summarize the best evidence for statins in the prevention and treatment of heart failure.

Recent Findings In patients with cardiovascular risk factors or established atherosclerotic cardiovascular disease (but without heart failure), statins reduce the risk of incident heart failure - mainly by preventing myocardial infarction although an additional benefit from reducing myocardial ischemia cannot be excluded. However, in patients with established heart failure, statins do not reduce the risk of cardiovascular death, which is mainly caused by pump failure and ventricular arrhythmias. Retrospective analyses, however, suggest that statins may reduce the rate of heart failure hospitalization and atherosclerotic events (which are proportionately much less common in these patients than heart failure hospitalization or death).

Summary Statin therapy should probably be continued in patients with coronary artery disease developing heart failure, although the weak evidence and small benefit may not justify the use of this treatment in very elderly patients with a short life expectancy and in which polypharmacy is a problem.
\end{abstract}

Keywords Statin $\cdot$ Heart failure $\cdot$ Prevention $\cdot$ Coronary disease

\section{Introduction}

Heart failure (HF) is a clinical syndrome characterized by a constellation of symptoms that may be accompanied by signs caused by a structural and/or functional cardiac abnormality, resulting in a reduced cardiac output and/or elevated intracardiac pressures at rest or during stress [1]. Two principal HF phenotypes are recognized- $-\mathrm{HF}$ with preserved ejection fraction $(\mathrm{HFpEF})$ and HF with reduced ejection fraction (HFrEF) [1]. The predominant etiology of HFpEF is hypertension and patients with this phenotype are older, more often obese, and more likely to be women than patients with HFrEF. Compared with HFpEF, patients with HFrEF generally are younger, more often men, and more likely to have coronary artery disease $[2,3]$.

This article is part of the Topical Collection on Statin Drugs

Matthew M. Y. Lee

Matthew.Lee.2@glasgow.ac.uk

1 Institute of Cardiovascular and Medical Sciences, University of Glasgow, Glasgow, Scotland
HF can be prevented by treatment of risk factors such as hypertension, obesity, and diabetes. Other treatments are also effective in slowing or preventing the development of HF after cardiac damage has occurred, e.g., the use of angiotensinconverting enzyme inhibitors after myocardial infarction (MI).

\section{Cholesterol Lowering in the Context of Heart Failure}

There is a recognized "cholesterol paradox" in this cardiac condition. That is, although raised plasma cholesterol is a causal risk factor for coronary artery disease (CAD), low serum total cholesterol is associated with poor prognosis in patients with established HF (in contrast to patients without HF) [4-9]. The question is, of course, to what extent this counterintuitive relationship represents "cause and effect." Notably, cholesterol has an inverse correlation with disease severity markers in other diseases (e.g., chronic kidney disease, severe rheumatoid arthritis) which have a strong inflammatory component $[10,11]$. Thus, possible reasons for the inverse association of cholesterol with HF are the finding that this lipid is known to be a marker of nutritional status (perhaps in part 
linked to greater systemic inflammation) in mild to moderate HF [12]. It is also possible that hepatic congestion (due to HF) could impair hepatic biosynthesis of cholesterol and so lower circulating levels since the liver is the main organ involved in lipoprotein production [5]. Another possible explanation is that HF causes intestinal congestion and therefore impairs cholesterol absorption, although this remains a hypothesis, with limited evidence [13]. In EVEREST, in 3957 patients hospitalized for worsening HF with left ventricular ejection fraction (LVEF) $\leq 40 \%$, both total plasma cholesterol and triglyceride exhibited a significant inverse relationship to outcome [14], whilst follow-up of a cohort of 305 HF patients over 20 years showed that low low-density lipoprotein cholesterol (LDL-C) levels may predict a less favorable outcome, especially in patients $<70$ years and those on statins [15]. Further, a lower high-density lipoprotein cholesterol is associated with worse prognosis in HF [16], as is low serum apolipoprotein A-I [17]. A German cohort study in 422 idiopathic dilated cardiomyopathy patients found that low cholesterol levels were dependent on the severity of cardiac disease [18], and a study of 288 very elderly patients hospitalized for medical conditions found that low LDL-C inversely correlated with N-terminal pro-B-type natriuretic peptide (NT-proBNP) [19]. The current working hypothesis is that lower plasma cholesterol is indeed secondary to the severity of patient's condition rather than an independent risk factor for poor outcome [20,21]. As noted above, this pattern is in line with other chronic conditions and thus observational data from people with such diseases must be interpreted with care.

\section{Statins in the Prevention of Cardiovascular Disease and Heart Failure}

It is well established that HMG-CoA reductase inhibitors (statins) reduce CAD events in patients with and without diagnosed cardiovascular (CV) disease. Clinical trial outcome data have been subject exhaustively to meta-analysis that has reinforced the findings of individual studies and "filled in" any gaps in the determination of efficacy in sub-groups in the population $[22,23]$. The main findings are the consistent demonstration that each $1.0 \mathrm{mmol} / \mathrm{L}$ reduction in LDL-C

\section{a}

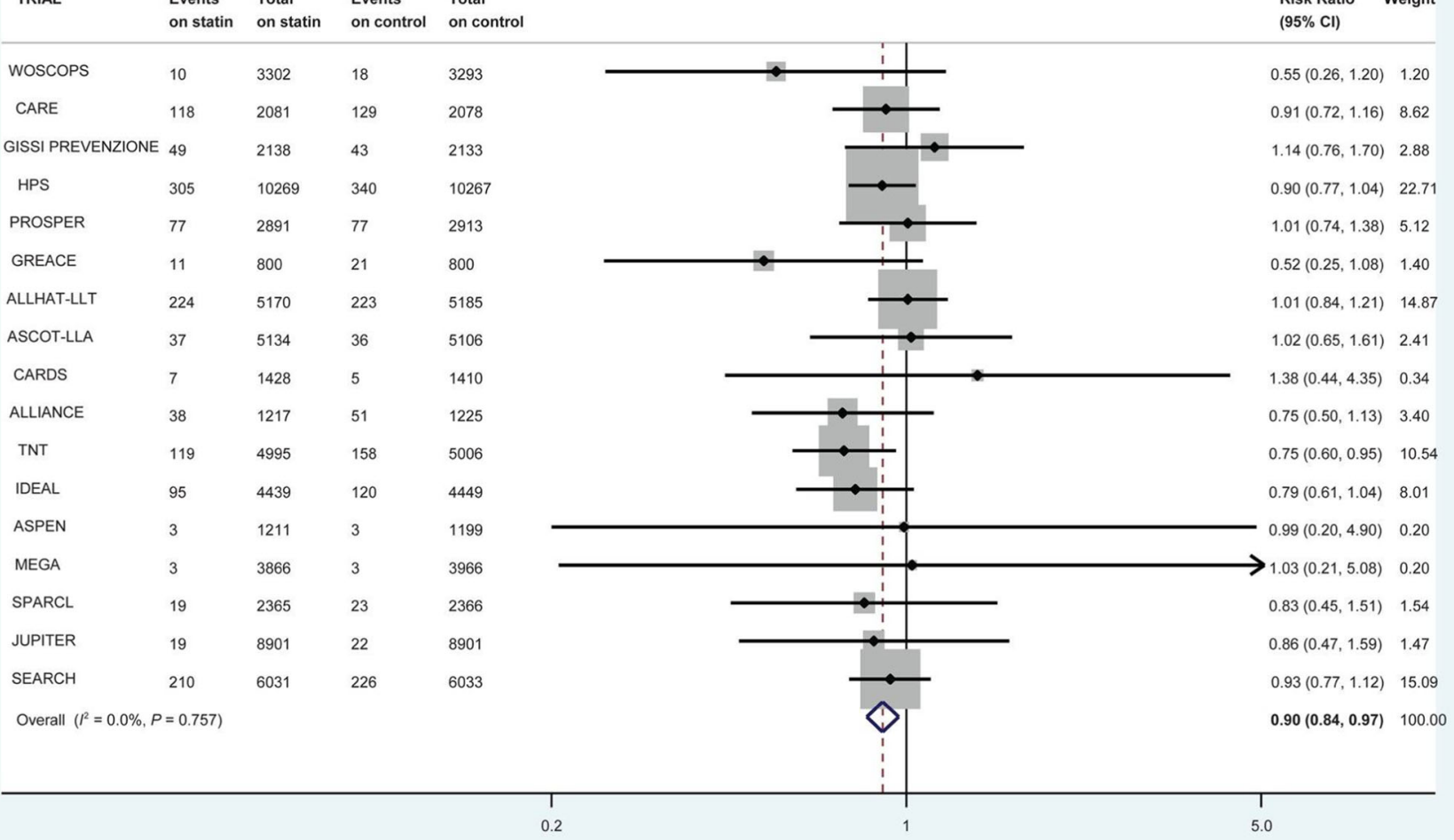

Fig. 1 The effect of statin therapy on the risk of first non-fatal heart failure hospitalization in 17 trials (a), heart failure death in 14 trials (b), and first composite heart failure outcome in 14 trials (c). All heart failure events within 30 days of myocardial infarction were excluded. Reproduced (as permitted by terms of the CreativeCommonsAttribution
License) (http://creativecommons.org/licenses/by/4.0/) from Preiss D, Campbell RT, Murray HM, Ford I, Packard CJ, Sattar N, et al. "The effect of statin therapy on heart failure events: a collaborative metaanalysis of unpublished data from major randomized trials." Eur Heart J. 2015;36:1536-46 
b

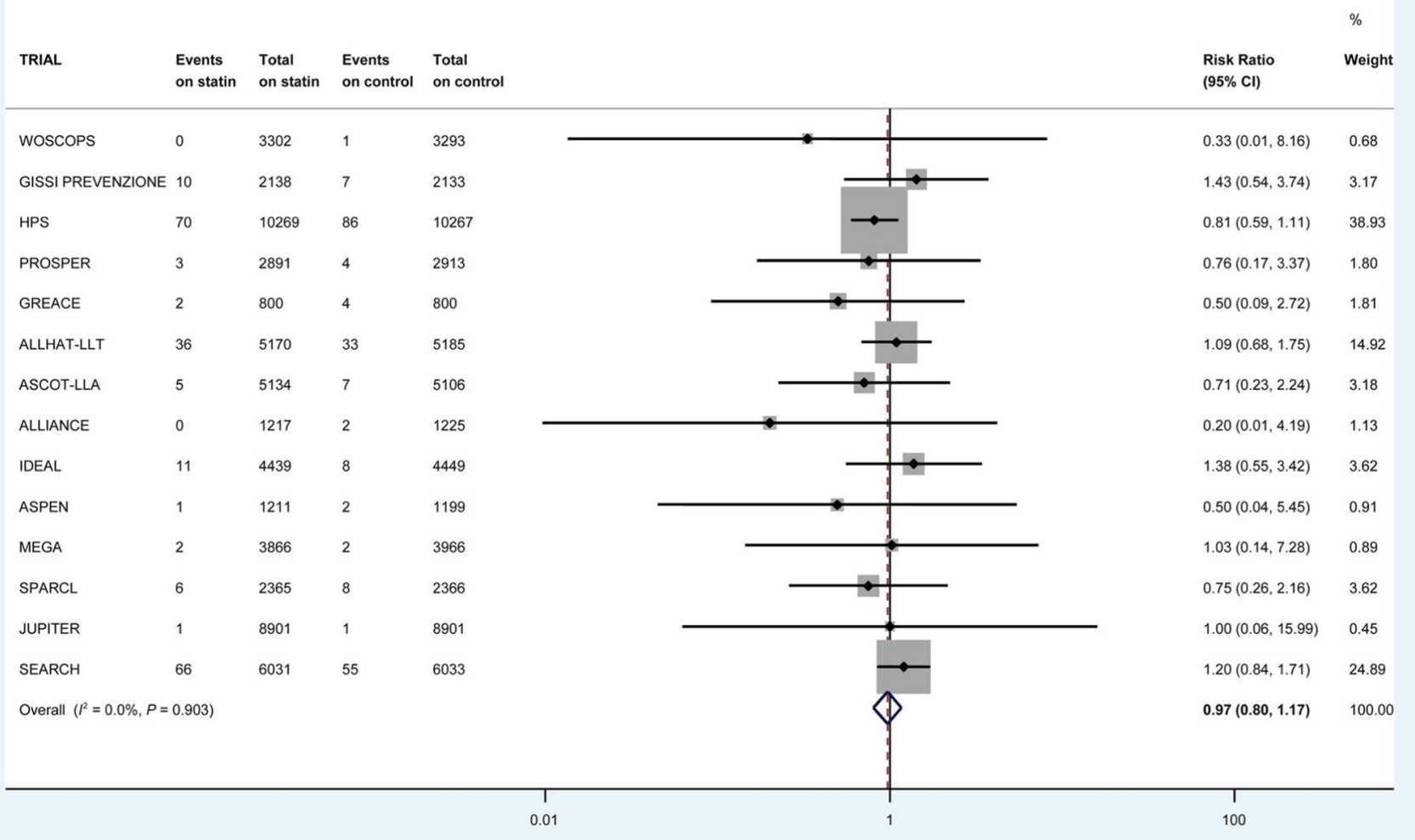

Fig. 1 continued.

C

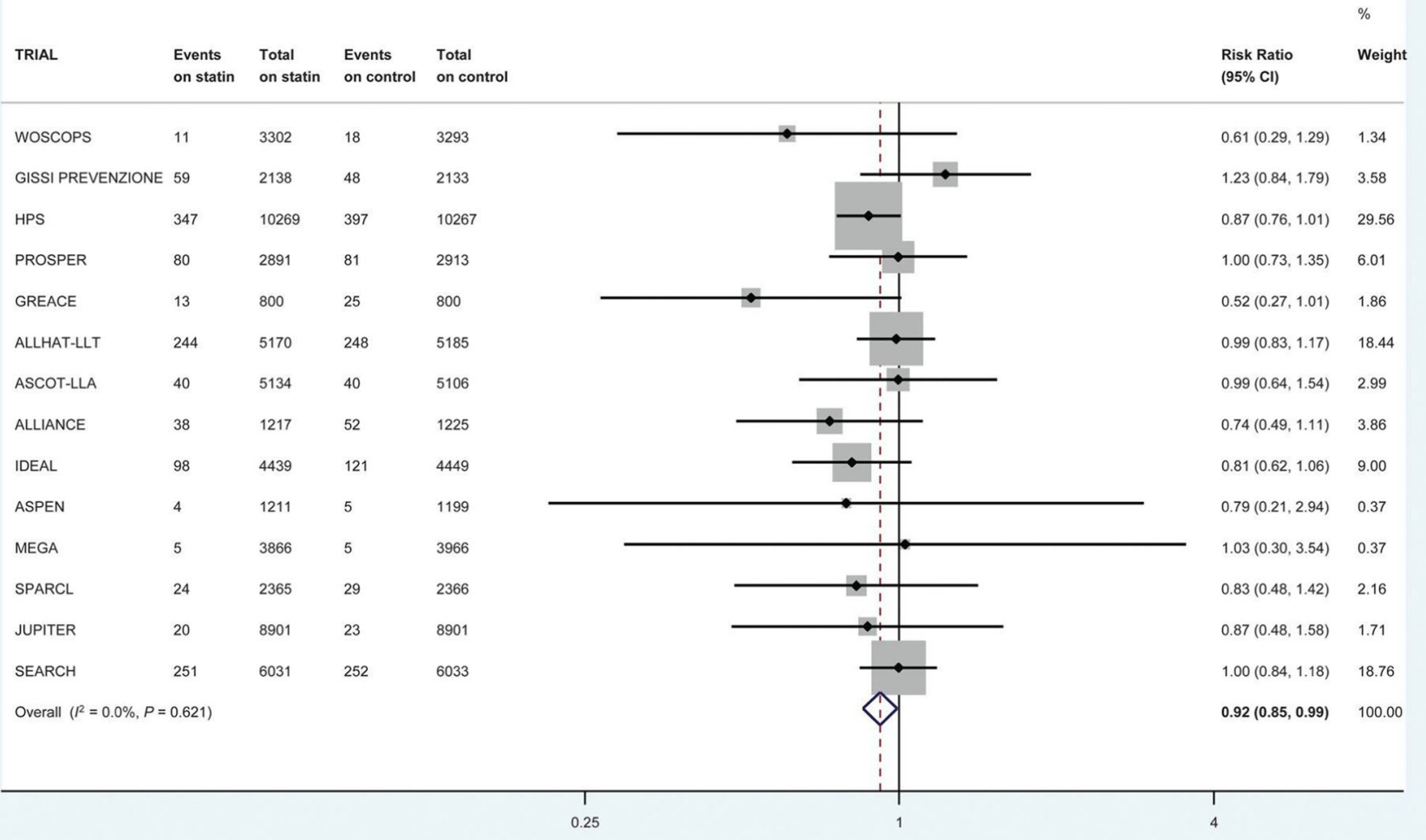

Fig. 1 continued. 


\section{Paths to heart failure in WOSCOPS 20-year follow-up}

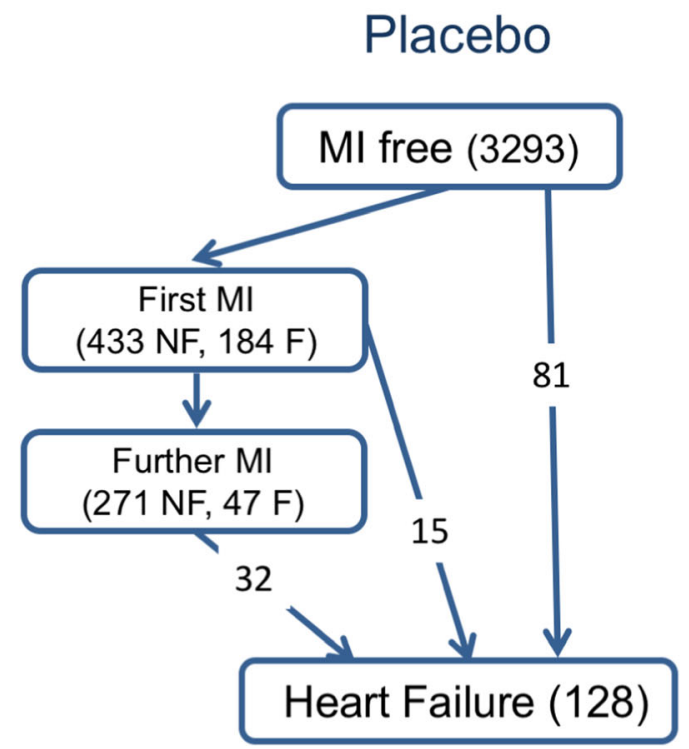

Fig. 2 In WOSCOPS, after 20 years of follow-up, of the total of 224 subjects hospitalized for, or dying from, HF, 75 (33\%) had incident MI preceding HF, whilst 149 (67\%) did not. HF events subsequent to MI were reduced by pravastatin treatment, compared with placebo ( 28 vs 47 ) $(p=0.022)$. Incident HF not preceded by MI was also less common in pravastatin-treated patients ( 68 vs 81 ), although the difference was not

decreases the risk of major vascular events by $22 \%$ (Cholesterol Treatment Trialists' (CTT) Collaboration which used individual level data on 170,000 in 26 trials) [24]. Ongoing concerns about statin therapy, particularly its safety, were addressed comprehensively in a meta-analysis in 2017 [25]. Further, there have been recent expert reports from The European Atherosclerosis Society (EAS) [26] and American Heart Association [27] on the issue of muscle-related side effects addressing their incidence rate and impact on adherence. To bolster the evidence base for statin therapy, extended follow-up data documenting safety and efficacy has become available for a number of trials including WOSCOPS [28, 29], ASCOT-LLA [30], and PROSPER which showed that even in the elderly, coronary protection was maintained in the longterm (mean follow-up 8.6 years) [31]. There is, however, a relative dearth of data from the major lipid-lowering trials on the effects of statin therapy on prevalent HF since most trials excluded patients with this syndrome [4, 32, 33]. For example, 4S [34] and LIPID [35] excluded patients with HF altogether, whilst CARE [36] and HPS [37] included only patients with mild to moderately severe symptoms and excluded those with severely symptomatic HF. HPS showed smaller reductions in major vascular events among those with greater baseline natriuretic peptide levels [38].

Some of these trials do allow us to look at incident heart failure. Collectively, these trials provide "reasonable evidence" that statin use can prevent or delay the onset of HF

\section{Pravastatin}

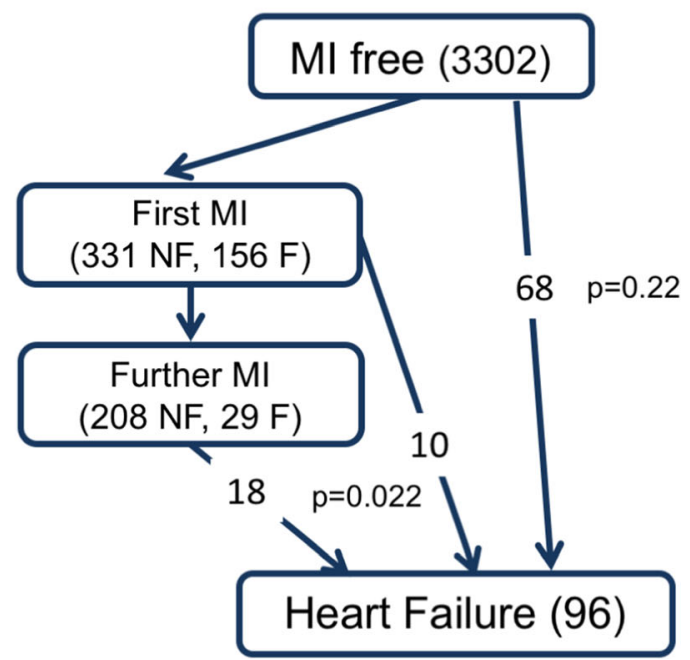

significant $(p=0.22)$. Abbreviations: $\mathrm{F}$, fatal; $\mathrm{HF}$, heart failure; $\mathrm{MI}$, myocardial infarction; NF, non-fatal; WOSCOPS, West of Scotland Coronary Prevention Study. Footnote: In subjects who experienced HF, the proportion with "antecedent MI" vs "no antecedent MI" does NOT differ between placebo and pravastatin groups $(p=0.24)$

[39-41]. This therapeutic link is based on the supposition that statins prevent MI and consequent cardiac damage and so reduce the risk of developing reduced ejection fraction HF. A meta-analysis of 6 randomized controlled trials (RCTs) of 110,271 patient-years in patients with recent acute coronary syndrome (ACS) showed that intensive statin therapy reduced hospitalization rates for HF [40]. Further, in a larger collaborative meta-analysis of up to 17 major primary- and secondary-prevention randomized trials with 132,538 participants conducted over 4.3 years, statins modestly reduced the risks of non-fatal hospitalization for HF (Fig. 1a) and the composite of non-fatal hospitalization or death from HF (Fig. 1c) but not HF death (Fig. 1b) [42••]. There was no demonstrable difference in risk reduction between those who suffered an incident MI or not [42••]. Interestingly, therefore, this benefit did not seem to be due to prevention of MI preceding HF.

Retrospective examination of individual trials also provides supportive evidence for a beneficial effect of statins on HF prevention. In $4 \mathrm{~S}$, simvastatin reduced incident HF by $19 \%$ [41], whilst in the post-ACS studies (PROVE IT-TIMI 22), intensive statin therapy reduced the rate of hospitalization for HF (especially if subjects had elevated baseline B-type natriuretic peptide (BNP)) [39], and in the TNT trial in patients with stable CAD, hospitalization for HF was lower in the intensive statin treatment arm [43]. Even in the primary prevention setting, if viewed over a sufficiently long time frame, statin therapy reduced the incidence of HF endpoints. 


\section{STATINS}

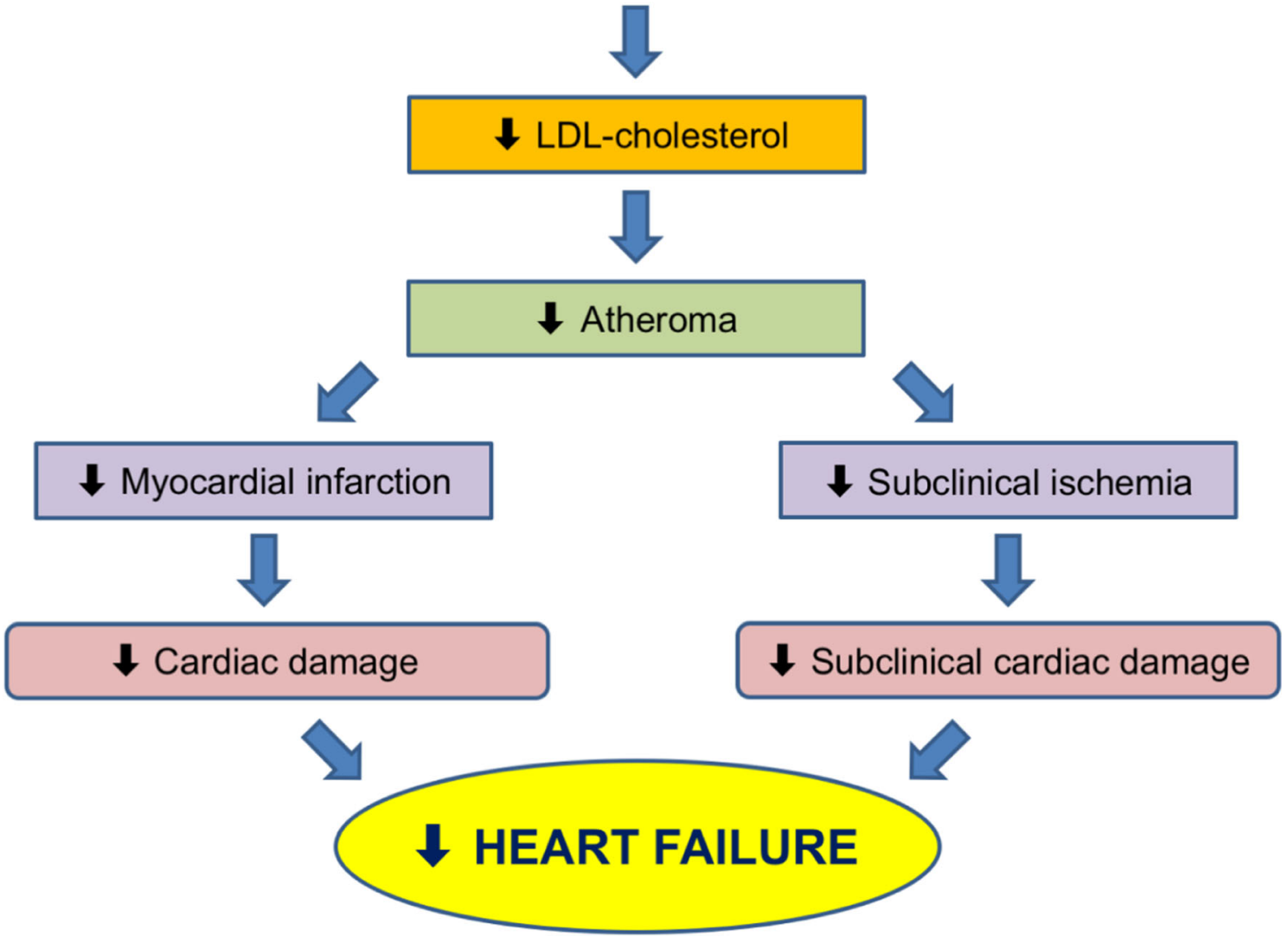

Fig. 3 Proposed mechanistic pathways on how statins reduce heart failure: (1) by reducing myocardial infarction; (2) by reducing subclinical ischemia (e.g., statins lower troponin levels in WOSCOPS). Abbreviations: LDL, low-density lipoprotein

In WOSCOPS, an initial 5 years of statin therapy led to a $35 \%$ reduction in the long-term (20-year) risk of hospitalization for HF [44••]. Of the total of 224 subjects hospitalized for, or dying from, HF, 75 (33\%) had incident MI preceding $\mathrm{HF}$, whilst 149 (67\%) did not (Fig. 2). HF events subsequent to MI were reduced by pravastatin treatment, compared with placebo (28 vs 47) $(p=0.022)$. Incident HF not preceded by MI was also less common in pravastatin-treated patients (68 vs 81$)$, although the difference was not significant $(p=0.22)$. This is consistent with the finding in the meta-analysis above that statins reduce HF risk through mechanisms additional to prevention of acute MI. Serial measurement of biomarkers such as NT-proBNP might have provided more support for this hypothesis but, unfortunately, NT-proBNP was measured only at 1 year after randomization in WOSCOPS [45].

\section{Statins in the Treatment of Established Heart Failure}

Cholesterol-lowering therapy with statins is not indicated in patients with moderate to severely symptomatic HF (New
York Heart Association (NYHA) class III-IV) according to the 2011 European Society of Cardiology (ESC)/EAS dyslipidemia guideline [46] and the updated 2016 ESC HF Guidelines do not recommend initiation of statins in most patients with HF, but continuation may be considered for those already on statins for prevention of CAD [1]. These recommendations are based largely on the findings of two major outcome studies CORONA [47] and GISSI-HF [48] that were large-scale placebo-controlled trials of statin treatment in subjects with NYHA class II-IV HF. CORONA recruited 5011 ischemic systolic HF patients aged $\geq 60$ years, whilst GISSI-HF included $4574 \mathrm{HF}$ patients of any etiology aged $\geq 18$ years. The active treatment arm used $10 \mathrm{mg} /$ day rosuvastatin in both trials, and median follow-up was 46.8 months in GISSI-HF and 32.8 months in CORONA. In GISSI-HF, the co-primary endpoints were time to death, and time to death or CV hospitalization. In CORONA, the primary endpoint was the composite of $\mathrm{CV}$ death, non-fatal $\mathrm{MI}$, or non-fatal stroke. No significant decrease in the primary composite mortality/morbidity endpoint was seen in actively treated subjects in either trial [47, 48]. However, CORONA did show that rosuvastatin therapy led to fewer CV 
hospitalizations [47], and in retrospective sub-group analyses, rosuvastatin appeared to provide more $\mathrm{CV}$ benefit in those with higher C-reactive protein [49] and lower baseline NTproBNP [50], and YKL-40 (chitinase-3-like protein 1) levels [51]. When repeat events were included in the CORONA endpoint analysis, rosuvastatin reduced hospitalization for HF by $15-20 \%$, but this was a post hoc analysis [52].

Not satisfied with the above trial evidence, a number of investigators have attempted to examine if statin therapy has any role in patients with established HF by examining randomized trials in a number of meta-analyses. For example, Zhang et al. reported no significant reduction from statin therapy for all-cause death, CV death, or rehospitalization for HF, but a non-significant trend to lower non-fatal MI [53]. Notably, however, CAD events are relatively uncommon in HF in general, even in ischemic HF, and are a minor contributor to the overall morbidity and mortality in patients with this condition [54]. The same group also investigated whether statin therapy had an effect on measures of left ventricular size and function, this time collating 11 RCTs totaling 590 patients [55]. Here they reported that statin use increased LVEF by $3 \%$ but notably, some of the trials were of modest quality, and there was considerable heterogeneity in the findings, so definitive conclusions cannot be made. Thus, whilst the best evidence suggests statins do not improve outcomes in patients with HF, clinicians generally continue HF patients on statins as most are not comfortable stopping them, unless statin-related complications arise.

\section{Potential Mechanisms by Which Statins Prevent HF Development}

Statins are believed to lower CAD by stabilizing atheromatous plaques, reduction of atheroma volume, and prevention of formation of new atherosclerotic lesions resulting in fewer MIs and less associated cardiac tissue damage. This may be the main way statins lower incident HF. We looked further at this in the long-term follow-up of WOSCOPS (Fig. 2) where, as noted before, it appeared that statin use decreased the incidence of HF. In a companion report, we found that pravastatin reduced high-sensitivity troponin I concentration by $13 \%$ [56 $]$ - and troponins also predict incident HF. Thus, it is theoretically possible that statins lessen "subclinical" ischemia and cardiac damage (Fig. 3). Whilst others have proposed a number of pleiotropic actions of statins (e.g., anti-inflammatory), there is no clear evidence for this contributing to clinical benefit [57].

\section{Non-Statin Lipid-Lowering Therapies in the Prevention of Heart Failure}

PCSK 9 inhibitors have not been found to affect HF hospitalisation (OR $0.98 ; 95 \%$ CI $0.86-1.13 ; P=0.79$ ) in a meta-analysis of 23 RCTs of 42,151 participants [58]. One ezetimibe randomized trial (HIJ-PROPER) of patients with acute coronary syndrome and dyslipidemia showed that HF hospitalisation was reduced in the intensive (pitavastatin + ezetimibe) vs. standard (pitavastatin monotherapy) lipid-lowering group, although the number of events was small $(n=59)$ and the $95 \%$ confidence interval around the estimate of treatment effect wide (HR 0.47; 95\% CI 0.27-0.81; $P=0.006$ ) [59]. The ACCORD and ACCORDION trial of fenofibrate showed no significant effect on congestive HF [60]. There are no robust data of the effect of niacin on HF.

\section{Conclusions and Clinical Implications}

There is robust evidence that in addition to lowering coronary heart disease (CHD), statins also lower risk for incident HF both in the medium and long term, although the extent of risk reduction is modest and far lower than the comparable benefits on CHD outcomes. By contrast, in patients with established HF, best evidence from two landmark trials does not support improved clinical outcomes with statins. Although statins may also lessen the chances of subsequent CAD events in HF patients (for which there is limited evidence in a metaanalysis of RCTs), few patients with HF actually die from acute $\mathrm{CAD}$ events and existing evidence is far from conclusive. Nevertheless, most clinicians generally do not stop statins in patients already prescribed these drugs and who subsequently develop HF. However, more judicious use of statins in the elderly HF patient with polypharmacy and a shorter life expectancy appears to be sensible.

Author Contribution CJP, JJVM, NS conceived the outline. MMYL wrote the first draft. All the authors read and approved the final version of the manuscript.

\section{Compliance with Ethical Standards}

Conflict of Interest Matthew M.Y. Lee, Naveed Sattar, John J.V. McMurray, and Chris J. Packard declare no conflict of interest.

Human and Animal Rights and Informed Consent All reported studies/ experiments with human or animal subjects performed by the authors have been previously published and complied with all applicable ethical standards (including the Helsinki declaration and its amendments, institutional/national research committee standards, and international/nation$\mathrm{al} /$ institutional guidelines).

Open Access This article is distributed under the terms of the Creative Commons Attribution 4.0 International License (http:// creativecommons.org/licenses/by/4.0/), which permits unrestricted use, distribution, and reproduction in any medium, provided you give appropriate credit to the original author(s) and the source, provide a link to the Creative Commons license, and indicate if changes were made. 


\section{References}

Papers of particular interest, published recently, have been highlighted as:

- Of importance

-• Of major importance

1. Ponikowski P, Voors AA, Anker SD, Bueno H, Cleland JGF, Coats AJS, et al. 2016 ESC guidelines for the diagnosis and treatment of acute and chronic heart failure: the task force for the diagnosis and treatment of acute and chronic heart failure of the European Society of Cardiology (ESC). Eur Heart J. 2016;37:2129-200.

2. Owan TE, Hodge DO, Herges RM, Jacobsen SJ, Roger VL, Redfield MM. Trends in prevalence and outcome of heart failure with preserved ejection fraction. N Engl J Med. 2006;355:251-9.

3. Meta-analysis Global Group in Chronic Heart Failure (MAGGIC). The survival of patients with heart failure with preserved or reduced left ventricular ejection fraction: an individual patient data metaanalysis. Eur Heart J. 2012;33:1750-7.

4. Catapano AL, Graham I, De Backer G, Wiklund O, Chapman MJ, Drexel H, et al. 2016 ESC/EAS guidelines for the management of dyslipidaemias. Eur Heart J. 2016;37:2999-3058.

5. Ananaba I, Taegtmeyer H. Low serum cholesterol as prognostic indicator in heart failure. J Card Fail. 2012;18:596.

6. Rauchhaus M, Clark AL, Doehner W, Davos C, Bolger A, Sharma $\mathrm{R}$, et al. The relationship between cholesterol and survival in patients with chronic heart failure. J Am Coll Cardiol. 2003;42:193340 .

7. Afsarmanesh N, Horwich TB, Fonarow GC. Total cholesterol levels and mortality risk in nonischemic systolic heart failure. Am Heart J. 2006;152:1077-83.

8. Horwich TB, Hernandez AF, Dai D, Yancy CW, Fonarow GC. Cholesterol levels and in-hospital mortality in patients with acute decompensated heart failure. Am Heart J. 2008;156:1170-6.

9. Weiss A, Beloosesky Y, Schmilovitz-Weiss H, Grossman E, Boaz M. Serum total cholesterol: a mortality predictor in elderly hospitalized patients. Clin Nutr. 2013;32:533-7.

10. Trevisan R, Dodesini AR, Lepore G. Lipids and renal disease. J Am Soc Nephrol. 2006;17:S145-7.

11. Robertson J, Peters MJ, McInnes IB, Sattar N. Changes in lipid levels with inflammation and therapy in RA: a maturing paradigm. Nat Rev Rheumatol. 2013;9:513-23.

12. Araújo JP, Friões F, Azevedo A, Lourenço P, Rocha-Gonçalves F, Ferreira A, et al. Cholesterol - a marker of nutritional status in mild to moderate heart failure. Int J Cardiol. 2008;129:65-8.

13. Chen Y, He XM, Meng H, Zhao QZ, Zhen YZ, Tian L, et al. Relationship between lipids levels and right ventricular volume overload in congestive heart failure. J Geriatr Cardiol. 2014;11: 192-9.

14. Greene SJ, Vaduganathan M, Lupi L, Ambrosy AP, Mentz RJ, Konstam MA, et al. Prognostic significance of serum total cholesterol and triglyceride levels in patients hospitalized for heart failure with reduced ejection fraction (from the EVEREST Trial). Am $\mathrm{J}$ Cardiol. 2013;111:574-81.

15. Charach G, Argov O, Nochomovitz H, Rogowski O, Charach L, Grosskopf I. A longitudinal 20 years of follow up showed a decrease in the survival of heart failure patients who maintained low LDL cholesterol levels. QJM. 2018;111:319-25.

16. Mehra MR, Uber PA, Lavie CJ, Milani RV, Park MH, Ventura HO. High-density lipoprotein cholesterol levels and prognosis in advanced heart failure. J Heart Lung Transplant. 2009;28:876-80.

17. Iwaoka M, Obata JE, Abe M, Nakamura T, Kitta Y, Kodama Y, et al. Association of low serum levels of apolipoprotein A-I with adverse outcomes in patients with nonischemic heart failure. J Card Fail. 2007;13:247-53.

18. Christ M, Klima T, Grimm W, Mueller HH, Maisch B. Prognostic significance of serum cholesterol levels in patients with idiopathic dilated cardiomyopathy. Eur Heart J. 2006;27:691-9.

19. Spannella F, Giulietti F, Cocci G, Landi L, Borioni E, Lombardi FE, et al. N-terminal pro B-Type natriuretic peptide is inversely correlated with low density lipoprotein cholesterol in the very elderly. Nutr Metab Cardiovasc Dis. 2018;28:629-35.

20. Skwarek M, Bilińska ZT, Mazurkiewicz Ł, Grzybowski J, Kruk M, Kurjata P, et al. Significance of dyslipidaemia in patients with heart failure of unexplained aetiology. Kardiol Pol. 2008;66:515-22.

21. Yoon CH, Youn TJ, Ahn S, Choi DJ, Cho GY, Chae IH, et al. Low serum total cholesterol level is a surrogate marker, but not a risk factor, for poor outcome in patients hospitalized with acute heart failure: a report from the Korean Heart Failure Registry. J Card Fail. 2012;18:194-201.

22. Cholesterol Treatment Trialists' (CTT) Collaboration, Fulcher J, O’Connell R, Voysey M, Emberson J, Blackwell L, et al. Efficacy and safety of LDL-lowering therapy among men and women: metaanalysis of individual data from 174,000 participants in 27 randomised trials. Lancet. 2015;385:1397-405.

23. Cholesterol Treatment Trialists' (CTT) Collaboration. Efficacy and safety of statin therapy in older people: a meta-analysis of individual participant data from 28 randomised controlled trials. Lancet. 2019;393:407-15.

24. Cholesterol Treatment Trialists' (CTT) Collaboration, Baigent C, Blackwell L, Emberson J, Holland LE, Reith C, et al. Efficacy and safety of more intensive lowering of LDL cholesterol: a metaanalysis of data from 170,000 participants in 26 randomised trials. Lancet. 2010;376:1670-81.

25. Collins R, Reith C, Emberson J, Armitage J, Baigent C, Blackwell $\mathrm{L}$, et al. Interpretation of the evidence for the efficacy and safety of statin therapy. Lancet. 2016;388:2532-61.

26. Stroes ES, Thompson PD, Corsini A, Vladutiu GD, Raal FJ, Ray KK, et al. Statin-associated muscle symptoms: impact on statin therapy-European atherosclerosis society consensus panel statement on assessment, aetiology and management. Eur Heart J. 2015;36:1012-22.

27. Newman CB, Preiss D, Tobert JA, Jacobson TA, Page RL 2nd, Goldstein LB, et al. Statin safety and associated adverse events: a scientific statement from the American Heart Association. Arterioscler Thromb Vasc Biol. 2019;39:e38-81.

28. Ford I, Murray H, Packard CJ, Shepherd J, Macfarlane PW, Cobbe SM, et al. Long-term follow-up of the West of Scotland coronary prevention study. N Engl J Med. 2007;357:1477-86.

29. Vallejo-Vaz AJ, Robertson M, Catapano AL, Watts GF, Kastelein JJ, Packard CJ, et al. Low-density lipoprotein cholesterol lowering for the primary prevention of cardiovascular disease among men with primary elevations of low-density lipoprotein cholesterol levels of $190 \mathrm{mg} / \mathrm{dL}$ or above: analyses from the WOSCOPS (West of Scotland Coronary Prevention Study) 5-year randomized trial and 20-year observational follow-up. Circulation. 2017;136: 1878-91.

30. Sever PS, Chang CL, Gupta AK, Whitehouse A, Poulter NR, ASCOT Investigators. The Anglo-Scandinavian cardiac outcomes trial: 11-year mortality follow-up of the lipid-lowering arm in the U.K. Eur Heart J. 2011;32:2525-32.

31. Lloyd SM, Stott DJ, de Craen AJM, Kearney PM, Sattar N, Perry I, et al. Long-term effects of statin treatment in elderly people: extended follow-up of the PROspective Study of Pravastatin in the Elderly at Risk (PROSPER). PLoS One. 2013;8:e72642.

32. Krum H, McMurray JJ. Statins and chronic heart failure: do we need a large-scale outcome trial? J Am Coll Cardiol. 2002;39: 1567-73. 
33. Kjekshus J, Dunselman P, Blideskog M, Eskilson C, Hjalmarson Å, McMurray JV, et al. A statin in the treatment of heart failure? Controlled rosuvastatin multinational study in heart failure (CORONA): study design and baseline characteristics. Eur J Heart Fail. 2005;7:1059-69.

34. Scandinavian Simvastatin Survival Study Group. Randomised trial of cholesterol lowering in 4444 patients with coronary heart disease: the Scandinavian Simvastatin Survival Study (4S). Lancet. 1994;344:1383-9.

35. Long-Term Intervention with Pravastatin in Ischaemic Disease (LIPID) Study Group. Prevention of cardiovascular events and death with pravastatin in patients with coronary heart disease and a broad range of initial cholesterol levels. N Engl J Med. 1998;339: 1349-57.

36. Sacks FM, Pfeffer MA, Moye LA, Rouleau JL, Rutherford JD, Cole TG, et al. The effect of pravastatin on coronary events after myocardial infarction in patients with average cholesterol levels. $\mathrm{N}$ Engl J Med. 1996;335:1001-9.

37. Heart Protection Study Collaborative Group. MRC/BHF heart protection study of cholesterol lowering with simvastatin in 20,536 high-risk individuals: a randomised placebo-controlled trial. Lancet. 2002;360:7-22.

38. Heart Protection Study Collaborative Group, Emberson JR, Ng LL, Armitage J, Bowman L, Parish S, et al. N-terminal Pro-B-type natriuretic peptide, vascular disease risk, and cholesterol reduction among 20,536 patients in the MRC/BHF heart protection study. $\mathrm{J}$ Am Coll Cardiol. 2007;49:311-9.

39. Scirica BM, Morrow DA, Cannon CP, Ray KK, Sabatine MS, Jarolim P, et al. Intensive statin therapy and the risk of hospitalization for heart failure after an acute coronary syndrome in the PROVE IT-TIMI 22 study. J Am Coll Cardiol. 2006;47:2326-31.

40. Afilalo J, Majdan AA, Eisenberg MJ. Intensive statin therapy in acute coronary syndromes and stable coronary heart disease: a comparative meta-analysis of randomised controlled trials. Heart. 2007;93:914-21.

41. Kjekshus J, Pedersen TR, Olsson AG, Færgeman O, Pyörälä K. The effects of simvastatin on the incidence of heart failure in patients with coronary heart disease. J Card Fail. 1997;3:249-54.

42.• Preiss D, Campbell RT, Murray HM, Ford I, Packard CJ, Sattar N, et al. The effect of statin therapy on heart failure events: a collaborative meta-analysis of unpublished data from major randomized trials. Eur Heart J. 2015;36:1536-46 An exemplary large collaborative meta-analysis of primary- and secondary-prevention randomized controlled endpoint statin trials.

43. Khush KK, Waters DD, Bittner V, Deedwania PC, Kastelein JJP, Lewis SJ, et al. Effect of high-dose atorvastatin on hospitalizations for heart failure: subgroup analysis of the Treating to New Targets (TNT) study. Circulation. 2007;115:576-83.

44.• Ford I, Murray H, McCowan C, Packard CJ. Long-term safety and efficacy of lowering low-density lipoprotein cholesterol with statin therapy: 20-year follow-up of west of Scotland coronary prevention study. Circulation. 2016;133:1073-80 In the landmark WOSCOPS trial, statin treatment was associated with cardiovascular benefits after extended ( 20 years) follow-up.

45. Welsh P, Doolin O, Willeit P, Packard C, Macfarlane P, Cobbe S, et al. N-terminal pro-B-type natriuretic peptide and the prediction of primary cardiovascular events: results from 15-year follow-up of WOSCOPS. Eur Heart J. 2013;34:443-50.

46. Reiner Z, Catapano AL, De Backer G, Graham I, Taskinen MR, Wiklund $\mathrm{O}$, et al. ESC/EAS guidelines for the management of dyslipidaemias: the task force for the management of dyslipidaemias of the European Society of Cardiology (ESC) and the European Atherosclerosis Society (EAS). Eur Heart J. 2011;32: $1769-818$
47. Kjekshus J, Apetrei E, Barrios V, Böhm M, Cleland JGF, Cornel $\mathrm{JH}$, et al. Rosuvastatin in older patients with systolic heart failure. $\mathrm{N}$ Engl J Med. 2007;357:2248-61.

48. Tavazzi L, Maggioni AP, Marchioli R, Barlera S, Franzosi MG, Latini R, et al. Effect of rosuvastatin in patients with chronic heart failure (the GISSI-HF trial): a randomised, double-blind, placebocontrolled trial. Lancet. 2008;372:1231-9.

49. McMurray JJV, Kjekshus J, Gullestad L, Dunselman P, Hjalmarson $\AA$, Wedel $\mathrm{H}$, et al. Effects of statin therapy according to plasma high-sensitivity C-reactive protein concentration in the Controlled Rosuvastatin Multinational Trial in Heart Failure (CORONA): a retrospective analysis. Circulation. 2009;120:2188-96.

50. Cleland JGF, McMurray JJV, Kjekshus J, Cornel JH, Dunselman P, Fonseca $\mathrm{C}$, et al. Plasma concentration of amino-terminal pro-brain natriuretic peptide in chronic heart failure: prediction of cardiovascular events and interaction with the effects of rosuvastatin: a report from CORONA (Controlled Rosuvastatin Multinational Trial in Heart). J Am Coll Cardiol. 2009;54:1850-9.

51. Arain F, Gullestad L, Nymo S, Kjekshus J, Cleland JG, Michelsen A, et al. Low YKL-40 in chronic heart failure may predict beneficial effects of statins: analysis from the controlled rosuvastatin multinational trial in heart failure (CORONA). Biomarkers. 2017;22:2617.

52. Rogers JK, Jhund PS, Perez AC, Böhm M, Cleland JG, Gullestad L, et al. Effect of rosuvastatin on repeat heart failure hospitalizations: the CORONA trial (Controlled Rosuvastatin Multinational Trial in Heart Failure). JACC Heart Fail. 2014;2:289-97.

53. Zhang S, Zhang L, Sun A, Jiang H, Qian J, Ge J. Efficacy of statin therapy in chronic systolic cardiac insufficiency: a meta-analysis. Eur J Intern Med. 2011;22:478-84.

54. Beggs SAS, Jhund PS, McMurray JJV. Anticoagulation, atherothrombosis, and heart failure: lessons from COMMANDER-HF and CORONA. Eur Heart J. 2018. https://doi.org/10.1093/ eurheartj/ehy609.

55. Zhang L, Zhang S, Jiang H, Sun A, Zou Y, Ge J. Effects of statin treatment on cardiac function in patients with chronic heart failure: a meta-analysis of randomized controlled trials. Clin Cardiol. 2011;34:117-23.

56. Ford I, Shah ASV, Zhang R, McAllister DA, Strachan FE, Caslake $\mathrm{M}$, et al. High-sensitivity cardiac troponin, statin therapy, and risk of coronary heart disease. J Am Coll Cardiol. 2016;68:2719-28 In this WOSCOPS analysis, troponin concentration is reduced by statin therapy.

57. Balk EM, Lau J, Goudas LC, Jordan HS, Kupelnick B, Kim LU, et al. Effects of statins on nonlipid serum markers associated with cardiovascular disease: a systematic review. Ann Intern Med. 2003;139:670-82.

58. Karatasakis A, Danek BA, Karacsonyi J, Rangan BV, Roesle MK, Knickelbine T, et al. Effect of PCSK9 inhibitors on clinical outcomes in patients with hypercholesterolemia: a meta-analysis of 35 randomized controlled trials. J Am Heart Assoc. 2017;6: e006910.

59. Hagiwara N, Kawada-Watanabe E, Koyanagi R, Arashi H, Yamaguchi J, Nakao K, et al. Low-density lipoprotein cholesterol targeting with pitavastatin + ezetimibe for patients with acute coronary syndrome and dyslipidaemia: the HIJ-PROPER study, a prospective, open-label, randomized trial. Eur Heart J. 2017;38:2264 2276.

60. Elam MB, Ginsberg HN, Lovato LC, Corson M, Largay J, Leiter LA, et al. Association of fenofibrate therapy with long-term cardiovascular risk in statin-treated patients with type 2 diabetes. JAMA Cardiol. 2017;2:370-380.

Publisher's Note Springer Nature remains neutral with regard to jurisdictional claims in published maps and institutional affiliations. 